\title{
Towards defending a semantic theory of expression in art: revisiting Goodman
}

\author{
Servaas de V. van der Berg \\ Department of Philosophy \\ University of Stellenbosch \\ Private Bag X1 \\ Matieland, 7602 \\ sdev@sun.ac.za
}

\begin{abstract}
Nelson Goodman's attempt to analyse the expressiveness of artworks in semantic terms has been widely criticised. In this paper I try to show how the use of an adapted version of his concept of exemplification, as proposed by Mark Textor, can help to alleviate the worst problems with his theory of expression. More particularly I argue that the recognition of an intention, which is central to Textor's account of exemplification, is also fundamental to our understanding of expressiveness in art. Moreover I propose that the recognition of this intention depends on our interpretation of the artwork - an insight Goodman tried to capture with his assertion that our attributions of expressive properties to artworks function metaphorically. The realisation of the context-dependence of our expressive judgements about art and, hence, of the central role interpretation plays in these judgements, I contend, counts in favour of theories of expression like Goodman's that focus on semantic concerns.
\end{abstract}

What do we mean when we apply emotion terms, like "joy" and "sadness", "anguish" and "rapture", to artworks and other lifeless objects? When calling a rendition of a Brahms intermezzo "melancholy" or a Wodehouse novel "jovial", whose feelings, if anyone's, are we describing? There is a rich literature dealing with these questions and in it a wide variety of answers articulated. ${ }^{\text {. One eminent answer was }}$ given by Nelson Goodman in Languages of Art $(1968)^{2}$, but his approach has fallen into disrepute since.

Goodman proposes that expression in art amounts to what he calls metaphorical exemplification, where exemplification is a restricted form of inverse denotation, and its metaphorical nature relates to the fact that attributing an emotion to an artwork is an instance of abnormal property ascription. Artworks, Goodman says, express emotions by (a) metaphorically possessing them as properties and (b) symbolising them in the way that samples symbolise (i.e. "exemplify") some of their properties. ${ }^{3}$ Goodman's theory has, however, rightly been criticised on both counts. Typically, his critics point out separate problems with his view of metaphor and with his notion of exemplification respectively. The objections in both cases are substantial but, I will argue, perhaps not insurmountable.

\footnotetext{
${ }_{2}^{1}$ For a concise overview of the main positions in the debate, see Matravers (2005).

${ }^{2}$ Note: references made to Languages of Art in this text are to the $2^{\text {nd }}$ edition of 1976 .

${ }^{3}$ Strictly speaking, in Goodman's nominalist view, it is labels and predicates rather than properties that are exemplified. However, it is a general habit in the secondary literature (a habit that even Goodman sometimes follows) to use semantic terminology ("labels" and "predicates") as well as ontological terminology ("properties") in explaining his theory. In this paper I will follow suit as, at any rate, I do not think the arguments presented here rest on the distinction.
} 
Recently Mark Textor has shown how, with some modifications, Goodman's notion of exemplification can be rescued from the standard criticisms. Textor (2008) supplements Goodman's version by making it an intention-dependent form of reference. It is doubtful whether Goodman would approve of this strategy, but Textor's suggestion goes a long way towards making exemplification into a useful theoretical tool where Goodman's own version came up short.

In what follows I take stock of the extent to which a reworked version of exemplification, like Textor's, can be used to salvage Goodman's theory of expression. The insight gleaned from Textor is that the main difficulties for Goodman's theory - not only with exemplification, but also with his view of metaphor - arise because his theory is rooted in an inadequate account of semantic reference. This might sound like an uncomplimentary stance towards Goodman. But on the contrary I want to argue that, whatever the particular flaws of his semantics, the view that expression in art can be analysed in semantic terms should not be discarded too hastily.

My argument will take the following form. In the first part, I give an exposition of Goodman's original account of expression and in the second, I explain the standard objections against it. Thirdly, I turn to Textor's analysis of exemplification and the promise it holds for salvaging Goodman's theory. In a fourth section, I argue that (something like) Textor's approach can also help to alleviate the worst of the concerns about the role of metaphor in our attribution of expressive properties to art. A short fifth section contains some concluding remarks.

\section{Expression as metaphorical exemplification}

Goodman's theory of expression was formulated as part of a more comprehensive semiotic account of art. For him, artworks are symbols that gain their symbolic function through participating in symbol systems. To be a symbol, for Goodman, simply means to "refer to" or "stand for" something else; a symbol system, then, is a set of characters along with everything they refer to. The set of characters considered in isolation, Goodman calls a "symbol scheme" (Goodman and Elgin, 1988: 126) and, moreover, within a given system the term "symbol" can designate either a single character or a compound of two or more characters (Goodman and Elgin, 1988: 124-125).

There are many different kinds of symbol systems, like the English language, the Roman numeral system, Western musical notation, the system of pictorial representation, etc. What differentiates these systems is not the type of reference that obtains in them (in fact reference is described as homogeneous in kind across different systems) but rather their syntactic and semantic features. Understanding what art is, then, becomes a question of understanding the symbol systems that artworks participate in - their syntactic and semantic traits as well as the nature and complexity of the referential relationships within them.

So, in order to defend his views about art, Goodman relies on what Jenefer Robinson (2000: 213) describes as 'a narrow semantic theory, which abstracts from the psychology of artists and audiences, and from the historical context of artworks, and which is consistent with his nominalism.' The primary form of reference in Goodman's account is denotation, reference that runs from a label or predicate to the object labelled or described. In this way, the phrase "is the first black American president", the term "water", and Picasso's portrait of Gertrude Stein, respectively denote Barack Obama, any and all instances of $\mathrm{H}_{2} \mathrm{O}$, and Gertrude Stein.

Denotation is, however, not the only form of reference recognised. Most notably, it is contrasted with exemplification - reference running backwards from an object labelled or described, to its label or predicate (or, in less strictly nominalist terms: from an object to one of its properties). Famously, Goodman (1976: 53) uses the example of swatches of cloth in a tailor's booklet to illustrate. The swatches function as samples that exemplify some, rather than other, of their properties. A particular swatch of cloth may for instance have several properties such as being "round", "of a coarse weave", "chequered", "small", "yellow", "less than an ounce in weight", etc. But while it possesses all of these properties, it normally exemplifies only "coarse", "chequered" and "yellow" rather than "round", "small" and "less than an ounce in weight". The swatch is not an aid for deciding on the shape or size or weight of the material one wants to buy; it is an aid for choosing the material's texture, pattern, colour, etc. In other words the swatch exemplifies those of its properties that it serves as a sample of. In the same way for instance Barack Obama, a bottle of water, and Gertrude Stein, may in the right contexts 
come to exemplify, say, black world leaders, transparent liquids, and women painted by Picasso. Exemplification, in all these cases, entails possession of as well as reference to a label or property.

Significantly, for Goodman exemplification, just like denotation, is entirely a function of the symbol system in use, rather than of facts about the nature of a particular symbol or about the psychologies of the persons using symbols to communicate. Reference, in Goodman's semantics, is conventional, and neither any natural link between a symbol and what it denotes, nor anyone's intentional use of a symbol is required to explain it. (As will become apparent later, while this stance is plausible regarding some instances of denotation, Goodman runs into trouble in his characterisation of exemplificational reference as resulting from nothing but an object's place in a symbol system.)

Exemplification is the cornerstone of Goodman's theory of expression. Artworks often exemplify aesthetically important qualities. The visible brush-strokes on Van Gogh's A Pair of Shoes could be said to exemplify its rough texture (like that of worn-down leather). In the ninth movement of SaintSaëns's Carnival of the Animals the clarinet part exemplifies the sound of a cuckoo bird. These are literal descriptions of qualities the artworks possess and refer to. Goodman draws a distinction, however, between exemplified properties that artworks "literally possess" and those that they "metaphorically possess". Among these latter we find the expressive properties of artworks.

\begin{abstract}
A symphony that expresses feelings of tragic loss does not literally have those feelings; nor are the feelings expressed those of the composer or spectator; they are feelings that the work has metaphorically and refers to by exemplification. (Goodman, 1981: 126)
\end{abstract}

On the one hand Goodman clearly demarcates his theory against those who want to tie the expressiveness of artworks to the mental states or intentions of the artist (so called "expression theories"), and on the other hand, against those that try to locate expressiveness in the experience of the audience ("arousal theories"). For him, the artworks themselves possess the emotions being expressed, albeit metaphorically, and the artworks themselves do the expressing, via exemplificational reference.

The idea of expression as metaphorical exemplification has a number of auspicious implications to commend it. Notably, other semiotic accounts of art have been criticised for focusing too much on the referential function of artworks, as this directs attention towards what is signified, whereas most artworks seem to attain their aesthetic status not through reference to what lies outside them, but through their own nature, through their own inherent qualities. The notion of exemplification allows Goodman's theory to avoid this criticism - while emphasising the referential function of artworks it also shows how reference is in many cases achieved via an artwork's possession of the qualities it refers to. This provides a reason for why we take our attention for the artwork itself as such an important feature of our interaction with art.

Another ostensibly happy consequence of Goodman's theory, Robinson (2000: 216) notes, is that it allows for the expression of non-emotional properties. If expression is metaphorical exemplification then not only emotions endure expression. Clearly it would not be wrong to say that some of Rodin's sculptures exemplify fluidity and movement, and these are without doubt not qualities they literally possess. Similarly, in the language of criticism, it surely makes sense to describe the onomatopoeia in Whitman's poem, "Beat! Beat! Drums!", as expressive of the sound of drumming. I will, however, follow Matravers (1998: 111-112) in admitting that there is an intuitive difference between these instances and the cases of expression wherein emotions are expressed. The latter I will take to be the paradigmatic cases and for this reason it makes sense for the rest of the paper to restrict the term "expression" to apply to emotions only.

\footnotetext{
${ }^{4}$ It turns out, in any event, to be easier to defend a version of Goodman's theory that takes expression to be just a sub-class of metaphorically exemplified properties. Goodman does not formulate such a restriction himself, but for the rest of this paper, I will add the condition to his theory that expression can only be the expression of emotional properties. The restriction saves Goodman's theory from some of the criticisms leveled in Davies (1991: 145-147) and, at any rate, it makes sense first to defend the restricted version and then to consider whether the restrictions can be slackened later.
} 
So, the question must be asked whether Goodman's theory gives an accurate analysis of those clearcut cases of expressiveness in which artworks are taken to embody human emotions. In light of this question some problems emerge. Among the main arguments against the theory, three in particular crop up repeatedly in the literature and, as such, require attention. The first pertains to Goodman's appeal to metaphor, the second and third to problems with his use of exemplification. Much of the rest of this paper will be concerned with showing how an adapted version of the theory might sidestep these objections. Before doing so, I shall briefly sketch the gist of each.

\section{The standard objections}

(1) The first argument against Goodman's theory tries to establish that his notion of metaphor is incapable of carrying the explanatory burden placed on it. A detailed articulation of this criticism can be found in Matravers (1998: 103-110). He correctly points out that Goodman is at a loss for explaining what exactly the "metaphorical possession" of a property entails. The point is this: our literal utterances that convey normal judgements or property ascriptions admit of truth conditions, but it is not clear that the same can be said of metaphorical utterances. When I say "the grass is green", there are obvious procedures to determine the accuracy of my claim, but when I make the (metaphorical?) claim "the grass is a bustling city", there are no such procedures readily available. What grounds are there to say that the latter claim is any more accurate a description of the grass than say "the grass is a cricket ball" or "the grass is Judith Butler"? In which cases then can we properly talk of metaphorical property ascriptions, and in which are we overstepping the line into gibberish?

One way to approach this problem is to focus on the justification we give for metaphors. After all, the difference between a normal judgement and a metaphor lies in the fact that the former does not require any justification, but the latter does. When I utter the claim "the grass is green", I do not need to cite any explanation for the sense of my utterance to be clear. But when I utter the claim "the grass is a bustling city", the sense of my utterance depends on the possibility of citing a relevant similarity between the grass and a city. I could for instance demonstrate that my statement is a metaphor by explaining how the grass is full of industrious living organisms, just like a bustling city. This would then justify the metaphorical claim. Without the possibility of such a justification, we cannot call a statement metaphorical. ${ }^{5}$

Why, one could ask, does this pose a problem for Goodman's claim that judgements attributing expressive properties are metaphorical? Ostensibly, Goodman is wrong in the first place to deny that metaphors necessarily have to admit of justifications. But this is not the only difficulty. The more fundamental issue is that, if a metaphorical utterance always requires justification, the question after the nature of the expressive qualities of artworks is left unanswered by Goodman's appeal to metaphor. Matravers (1998: 103) argues that a theory of expression worth its salt should be able to rationalise the link between the central use of human emotion terms and their aesthetic use. To succeed in this, one has to do more than claim that their aesthetic use is metaphorical - in fact, one has to say something about what justifies their use in aesthetic contexts. Goodman's theory, it appears, fails to do this. I will return to this problem in the fourth section of this paper.

(2) A second line of criticism against Goodman that deserves consideration goes something like this: According to Goodman, expression in art entails exemplification and thus relies on an artwork's possession of expressive properties as well as the symbolic function of referring to those properties. But if exemplificational reference requires an artwork's prior possession of the properties exemplified, then what is really called for from a theory of expression is an account of what it means for an artwork to possess them. As Davies (1991: 140) puts it: "if the work already possesses the property of being sad, say, then expressiveness is a matter of possession rather than exemplification". Goodman's theory comes up short in that it fails to explain how artworks acquire their expressiveness, while giving all its attention to how that already present expressiveness is used for referential purposes.

(3) The third shortcoming is with the concept of exemplification itself. Margolis (1981), Davies (1991: 142-145), Matravers (2005: 448), and Textor (2008: 348-351) have all pointed out that exemplification

\footnotetext{
${ }^{5}$ Note that this does not necessarily imply that the cited justification would exhaust the entire content or effect of the metaphorical utterance. The claim is just that metaphorical utterances must at least admit of some such justificatory citation, in a way that literal sentences do not. (Matravers 1998: 109f)
} 
is under-analysed in Goodman's account. The problem stems from the "narrow semantic theory" in which Goodman grounds exemplification - a semantics that attempts to explain all reference as the upshot of nothing but the conventions regulating a symbol system. This is indeed a plausible way to understand certain cases of denotation:

I take the point to be this: where the conventions of a symbol system are established, they do their work independently of their being used intentionally. A picture might have [...] a representational character when viewed in terms of the relevant conventions for representation, whether or not those conventions were deliberately employed. And we might concern ourselves with the meanings of words or sentences without regard to what was or might have been meant by them on any particular occasion. (Davies 1991: 141)

Symbols sometimes achieve their reference without having been intentionally used to do so. But Goodman seems to be committed to the view that where there is any kind of reference, this is always the case. On closer inspection it becomes clear that this view will not work in most cases of exemplificational reference.

The appeal to conventions or to the rules that regulate a symbol system may in particular situations be good enough to secure denotative reference ${ }^{6}$, and hence, to determine some of the properties (labels/predicates) an object possesses. In the case of exemplificational reference, however, this is not enough. What is required is a criterion to decide which of an object's properties it merely possesses, and which of its properties it actually refers to and hence exemplifies. Goodman's appeal to the rules of the symbol system provides us with no such criterion. To the question "which properties does an object exemplify?" Goodman (1976: 93) answers: those that it displays. But this is hardly an informative answer. What does it mean to display a property? Goodman's answer: it means to exemplify it. The circularity is blatant. We need a way to distinguish between exemplified and merely possessed properties and Goodman's semantics does not have a ready solution.

Textor gives an analysis of exemplification that solves this third problem. After explaining his view I will argue that his adapted version of exemplification also provides the key to answering the first and second complaints raised in this section.

\section{Rescuing exemplification}

In Textor's view, objects exemplify properties when they are used by someone to do so. Where Goodman's theory had the regrettable tendency of treating artworks anthropomorphically, as if they themselves select the properties they wish to display or highlight ${ }^{7}$, Textor recognises that the paradigm setting for exemplification is one that involves human agency.

Goodman talks frequently as if a sample or work of art itself calls attention to some of its properties. But works of art don't call attention or make manifest properties, people do so. (Textor 2008: 351)

Exemplification then, in its typical form, is an act of communication that takes place between people when a person uses an object to stand as a sample of some or other class of states or objects. Central to this act of communication, Textor shows, is the recognition of an intention. I shall use one of Textor's (2008: 255) examples to illustrate:

When the concertmaster plays a note on his violin before an orchestral performance, he exemplifies the pitch of the note. ${ }^{8}$ What is required for the communicative act of exemplification to be successful is

\footnotetext{
${ }^{6}$ Note that this is only sometimes the case. I agree with Davies (1991: 143f), that explaining denotation (and hence property possession) in this way is also problematic, as there are cases where the intentional use of a symbol is also required to secure denotation. This becomes relevant when I try to give an account, in Section 3, of what the metaphorical possession of properties might entail, i.e. of how denotation can be understood in the case of metaphorical utterances.

${ }^{7}$ Cf. Margolis (1981: 267).

${ }^{8}$ One could also say "the note exemplifies its pitch". Textor does switch between talk of people using objects to exemplify properties and the objects exemplifying properties themselves. But he defines the
} 
not just for the orchestra members to become aware of the pitch of the note. If this was all, then one could hardly take exemplification to be a form of reference. The orchestra members also need to recognise the concertmaster's intention that they become aware of the pitch. Differently put, for a successful act of exemplification there is not only a need to become aware of the property being exemplified; there is the need to become aware of it in a certain way.

It is this idea, of becoming aware of an object's property in a particular way - i.e. as a property belonging to a certain kind of states or objects - that captures the referential nature of exemplification. The awareness involved in our perception of a sample is not just an awareness of the sample's property; it is simultaneously the awareness that this is what the property is like. When the concertmaster plays a note on the open A-string, the orchestra members do not simply hear the pitch of an A, they hear it as the pitch that their own instruments might and should have when they play an A during the concert.

This, I want to argue, is a particular case of aspect-perception or "perceiving-as", one that necessarily results from an act of exemplification. If $I$ do not know what a hummingbird is and someone exemplifies it to me by pointing it out in a picture, I do not merely see the hummingbird, I see the hummingbird as a hummingbird. My perception of the hummingbird becomes a perception of what it is like to be a hummingbird, and it does so in virtue of my recognition of the intention with which it is pointed out to me. This last point is essential: one could in all kinds of circumstances observe hummingbirds under the aspect of what it is like to be a hummingbird, but in a case of exemplification, this aspect becomes salient in a way that it would not normally be. The reason for its becoming salient is the perceiver's recognition of the intention with which the hummingbird is being pointed out. ${ }^{9}$

Textor's analysis thus gives us an intentionalist account of how exemplificational reference comes about. Clearly, this is directly in conflict with Goodman's self-imposed task of analysing reference in art in terms of the conventions that regulate symbol systems only. But the way that Textor supplements Goodman's notion of exemplification allows him to solve some problems that Goodman's "narrow" semantics had no answers for. The most obvious advantage of his analysis is that it solves the third objection discussed in the previous section - it provides a criterion for distinguishing between the properties an object exemplifies, and those it merely possesses. An object exemplifies only those of its properties it is intended by someone to exemplify in a particular context. The intention functions as criterion for the distinction.

Up to this point, however, the account pertains to paradigm cases of exemplification, but of course one might point out that there are also instances of exemplification where there is no active intention at work. Textor (2008: 357), rightly, allows for this: "The regular use of objects with a particular intention may give rise to a practice or social convention of using an object to exemplify specific properties. This seems to be the natural description of our understanding that swatches of cloth exemplify texture and colour, but not size." If there is a social convention like this, clearly it is not always necessary for a specific conscious intention to ground our recognition of objects as samples. ${ }^{10}$ The reason is that such a social convention stipulates a generally established intention: say, that objects of a certain kind or within a certain context are intended for making us aware of certain of their properties.

latter case simply as a corollary of the former inasmuch as an object can only exemplify something if it is being used by someone to do so - i.e. if there is an intention that it should do so.

${ }^{9}$ It may be pointed out that the kind of perception I am describing here seems closer to the Wollheimian notion of "seeing-in", than it seems to "seeing-as" or aspect perception. After all, seeingin, in Wollheim's (1987) account, is also a perception based in someone's intention. The main difference is that I do not take the intention required for exemplification as providing a standard of correctness for deciding which emotions we can properly perceive an artwork as expressing. In fact, as will become clear, a more general and institutionalised kind of intention - the intention that we perceive artworks as expressive as such, rather than as expressive of particular emotions - is enough to give rise to exemplification.

${ }^{10}$ This is probably why Goodman was tempted into thinking that one could analyse exemplification in terms of the conventions regulating a symbol system. But the kind of convention in question here is not typical of the conventions that govern the syntactic and semantic structure of a symbol system. It is a convention, rather, that encompasses an intention for how certain objects should be perceived. 
This is exactly the kind of exemplification that normally takes place in art. Plainly, in our appreciation of art, there are standing practices that many of the aesthetically significant qualities of artworks, including their expressive ones, should be perceived in terms of an intention. This need not on every particular occasion be a conscious intention of, say, the artist or the performer or anyone with a specific relation to the artwork. ${ }^{11}$ Specific conscious intentions like these may of course sometimes, or even often, come into play. But there are also practices or conventions that establish the general intention that particular kinds of qualities should be concentrated on in our appreciation of art.

Textor's analysis thus solves the conceptual problems with Goodman's notion of exemplification. So far, so good. In my view, his focus on the role of intentions in exemplification also gives us the purchase we need to answer the second complaint raised in the previous section. That issue was namely that exemplification requires that an object possesses the property it is used to exemplify; hence, if artworks already possess expressive properties prior to exemplifying them, then accounting for their expressiveness is a matter of accounting for possession rather than exemplification.

The solution to this problem, I believe, and I depart from Textor's position in this ${ }^{12}$, lies in denying that exemplification always requires an object's prior possession of the properties exemplified. My contention is that this is indeed plausible, because the expressive properties of artworks are in fact partly constituted by their being exemplified. What I mean is that, in the case of expressive properties, the intentions that Textor made into a criterion for their exemplification are in fact also required to secure their possession. In other words, a work could only possess sadness, for instance, inasmuch as it can be understood as exemplifying sadness. It is the use the work is put to - that of exemplifying a human emotion, say sadness, and hence the use of giving experiential evidence of what sadness is like - that prompts us to judge that the work is sad at all.

The argument that expressiveness is a matter of possession rather than exemplification overlooks the fact that when we become aware of an artwork's expressive properties, we invariably become aware of them in light of a social convention surrounding art that includes the general intention that we should attend to these properties. Artworks are intended to be perceived as expressive; to perceive an artwork without recognising this intention is to perceive it as something other than an artwork. If I am right in this, then we only ever become aware of expressive properties as properties of a certain kind i.e. as properties exemplified. Expressive properties are nowhere present without the implicit intention that we perceive them as such - which means they are never possessed by an object without also being exemplified. Hence, Goodman was right: expressiveness in art is conceptually dependent on exemplification. Exemplification is part of what it means for an artwork to be expressive.

One of the further reasons why this is an attractive solution is that construing expression as I have done, in terms of an intentionalist account of exemplification, allows us to answer two important question about our experience of expressiveness. Firstly, the question of how expressive properties come to be part of our experience of a work:

As we have seen, it would be a mistake to assume that all that needs explaining is the use of emotion terms in aesthetic contexts. The experience also needs explaining: how do emotions 'enter into' the experience of objects which cannot feel...? (Matravers, 1998: 145)

In discussing Textor's version of exemplification it became apparent that when a property is successfully exemplified we become aware of it in a particular way. Our awareness goes beyond mere awareness of the property in question to the awareness that "this is what the property is like". If expressive properties are as I have argued always exemplified properties, then this explains why we experience them as intimately tied to the artworks they belong to. Our perception of an artwork in fact becomes our point of direct epistemic access to the emotion exemplified; the work allows us to experience firsthand what the exemplified emotions are like.

\footnotetext{
${ }^{11}$ The implication that exemplification in art need not privilege the intentions of the artist is fortunate. It means that Textor's adapted version of exemplification can be used without risking the pitfalls encountered by other intentionalist accounts of expression.

${ }^{12}$ Cf. Textor (2008: 257).
} 
Secondly, the account of exemplification given here also clarifies why the appropriate response to an expressive artwork, over and above that of forming the belief that the artwork is sad or exuberant or anguished or what have you, is to feel some kind of emotion oneself (ibid.). Apart from calling our attention to the relevant attributes of the work itself, the exemplification of emotional properties prompts us to compare those attributes with our own stock of experiential acquaintance with the properties exemplified. In this way, when I listen to sad music in the appropriate circumstances, feelings of sadness that I am acquainted with from previous experience are called up. Such feelings in the appropriate listener form part of the signified in the referential relationship established in exemplification.

\section{Reconsidering the role of metaphor}

I have addressed the second and third objections raised in Section 2, but the first still remains. What does it mean for an object to "metaphorically possess" a label, predicate or property? This is an important question, because showing that Goodman's concept of exemplification can be salvaged has not yet helped us towards an account of the actual nature of the expressive properties that artworks purportedly exemplify. I have argued so far that it is part of their nature that they are always exemplified by the artworks they belong to. This cannot, however, be more than a partial analysis, because showing that aesthetic expressiveness depends on exemplification is only to point out a salient difference between expressiveness in the central cases and expressiveness in art. A full analysis requires that we explain not only the differences, but also the link between the normal emotions and emotions in art. More specifically: what justifies our application of emotion terms (that paradigmatically apply to sentient human beings) to insensate objects like artworks?

Goodman appeals to metaphor for an account of this link: artworks do not literally possess expressive qualities, they have them metaphorically. But the complaint against his view is that the appeal to metaphor lacks explanatory bite. The main reason why Goodman fails to defend his view against this complaint, I think, lies once again in the inadequacy of his semantic theory. Here Textor's insights about the shortcomings of Goodman's semantics come in handy. To speak of an artwork as metaphorically possessing a predicate or label is once more to treat it anthropomorphically - as if the artwork itself secures the connection to the predicate applied to it in a metaphor. But, to borrow Textor's phrase, works of art don't make metaphors, people do so!

The issue is that Goodman once again relies too heavily on a semantic theory in which symbol systems have to do all the work. Recall that he tries to explain denotation (and hence an object's possession of the labels or predicates that denote it) in terms of the conventions regulating a symbol system. Leaving aside the question whether this is an adequate account of denotation in normal, literal utterances - in the case of metaphorical utterances it simply will not do. The conventions regulating a symbol system cannot provide a criterion to determine which predicates apply to an object metaphorically and which do not, because metaphors consist precisely of the deviant application of predicates. In metaphors predicates are applied to objects they do not denote under usual circumstances. This is why metaphorical utterances require justification over and above the appeal to their participation in a symbol system.

If we then, like Goodman, construe our expressive judgements (with which we attribute emotional properties to artworks) as metaphorical, we need an account of what justifies the metaphors in question. Goodman's theory provides no such account. Also, if justification for expressive judgements is the thing that a theory of expression is supposed to provide, one might well argue that the recourse to the concept of metaphor is redundant. Explain the expressive judgement's justification, and you have already explained the judgement itself. Such objections to Goodman's account, however, miss the point, and I will try to show how.

Let us first consider utterances that are indisputably metaphorical. The question about the justification of a metaphor is not a question with a general answer. In fact, it is usually aimed at determining the intention with which a metaphor was formulated. Now, in the analysis of exemplification given in the previous section it became conceivable that there is a particular kind of intention at work in our perception of expressive artworks - an intention that prompts us to perceive the artworks in terms of, or as samples of, emotional properties. Given this kind of intention, our experience of an emotional property of an artwork becomes an experience that "this is what the property is like". 
Also in the previous section, I argued that exemplification is part of what it means for an artwork to possess an expressive property - that we become aware of expressive properties always already as exemplified properties. If this much is right, then it seems reasonable to assume that the same intention that grounds the artwork's exemplification of the property in question, also grounds its possession of that property. It is, in other words, this same intention that also establishes the link between the artwork and the emotion. Alternatively put (in hypothetical terms): it is the intention behind the metaphor. We come to perceive artworks under the aspect of sadness or joy or anger or jubilation, I propose, because we recognise them as being intended to be perceived that way.

There is a problem with this hypothesis that still needs ironing out. Recall that the intention required to establish exemplification was characterised in the previous section as something that could either be a particular intention of the artist or a critic or the performer etc., or it could be a social convention that encompasses the general intention that emotional properties should be attended to in art. The problem is that, while in the former case of particular intentions it is easy to determine a criterion for which emotion it is appropriate to perceive a work as exemplifying, the same cannot be said for the latter case. How are we to determine, with reference to the general intention that artworks should be appreciated as exemplifying emotions, which emotions it is appropriate to look for in which artworks?

The clue, I would argue, lies in the fact that we clearly take some metaphors to be more apt than others, and some justifications for metaphorical utterances as better (or more likely to match the intentions of the person who established the metaphorical connection) than others. Just like Eliot's metaphor 'the burnt out ends of smoky days' ${ }^{\prime 13}$ is a more apt description of a city winters evening than, say, 'the green ball of cantankerous twilight' would have been; so perceiving Tolstoy's Anna Karenina under the aspect of grief is more apt than perceiving it under that of exuberance. But, in the case of metaphors in general, on what do we base our judgements to this effect? Are they based on some objectively given standard determining the aptness of metaphors, or perhaps on a universally applicable measure determining the probable intentions with which metaphors are formulated? Surely not. Judging the aptness of a metaphor is a highly context-dependent affair. Just so, the judgement that a particular artwork possesses and expresses a particular emotion does not have to depend for its veracity on one specific kind of reason.

My answer to the question of what justifies the application of an expressive property to an artwork hence leads to a kind of pluralist analysis of expressiveness. The similarities between human emotions and the artworks that exemplify them come in many different kinds. This is the point: to describe a passage from Tolstoy's Anna Karenina as sad is different to describing Liszt's Totentanz as sad, which in turn is different to describing Mary Frye's poem "Do not stand at my grave and weep" as sad. In each different case one could give a different justification for describing the work as sad. Sometimes, different justifications are even to be had for perceiving one and the same work as having a particular expressive property.

This is in keeping with the way a metaphor works. Recall that, for the metaphor "the grass is a bustling city" I could cite the explanation that it is full of industrious living organisms. I might however also have explained that, from the perspective where I am lying on the grass, the blades cut at different lengths resemble a city's skyline, or that the wind blowing through the grass makes a noise that reminds me of the humdrum of a busy metropolis. Depending on the intention with which the metaphor was formulated, the justifications I could give might differ greatly. In the end, deciding which of the similarities that hold between the grass and a bustling city are relevant to the justification of my (admittedly rather clumsy) metaphorical statement, is not something that depends on the inherent qualities of the grass only. It is a matter of interpretation. And so is our recognition of expressiveness in art.

Goodman's appeal to metaphor has merit exactly because it does not, like other accounts, reduce the possible justifications we can give for our expressive judgements to a univocal or a singular type of reason. The purpose of expression in art is after all (at least in part) to show us novel and widely different ways in which the world can be experienced. Correctly judging of an artwork that it is sad or joyful or angry or jubilant is therefore just as much to recognise something about sadness, joy, anger

\footnotetext{
${ }^{13}$ From "Preludes I".
} 
and jubilation as it is to recognise something about the artwork itself. The analysis of expression in terms of metaphor captures this better than it could be accounted for by any analysis that tells us exactly and exhaustively what it means, or what justifications may legitimately be given, to call a sad artwork sad or a joyful artwork joyful.

\section{Concluding remarks}

I have argued that an adapted version of Nelson Goodman's theory of expression - expression understood as metaphorical exemplification - can be rescued from the criticisms typically levelled against it. The following adaptations and supplements to Goodman's theory were made along the way:

In Section 1 I restricted Goodman's theory to allow for the expression of emotional properties only. In Section 3 I argued, firstly, following Textor, that exemplification depends on the recognition of an intention; and secondly that this analysis provides the necessary grounds to defend Goodman's idea that expression in art is conceptually dependent on exemplification. In Section 4 I argued that the intention that Textor makes criterial for an artwork's exemplification of a property is the same that grounds the artwork's possession of that property. Differently put, because we recognise that an artwork is intended for making us aware of an emotional property, we come to perceive the artwork under the aspect of that property. Moreover, I tried to show that Goodman's appeal to metaphor is best read as reflecting the following insight: that pinpointing the particular content of the intention involved in expressiveness is a matter of interpretation in a way similar to how recognising the cognitive content of a metaphor depends on interpretation.

Matravers (1998: 109-110), following Walton (1973: 298-299), has argued against Goodman's use of the notion of metaphor on the grounds that there are some significant disanalogies between unproblematic, everyday instances of metaphor on the one hand, and our attributions of expressive properties to art on the other. Admittedly I have given Goodman an overly sympathetic reading on this score, while I am actually inclined to agree that these disanalogies pose a real threat to the view that expressive aesthetic judgements are in fact metaphorical. Yet I still want to maintain the spirit of Goodman's appeal to metaphor by granting that he is right to analyse expressive property attributions in semantic terms, especially because of the role this affords to interpretation in those attributions.

\section{References}

De Clercq, R. 2005. "Aesthetic Terms, Metaphor, and the Nature of Aesthetic Properties". Journal of Aesthetics and Art Criticism. 63(1): 27-32.

Goodman, N. 1976. Languages of Art. $2^{\text {nd }}$ Edition. Indianapolis: Hackett.

Goodman, N. 1979. "Metaphor as Moonlighting". Critical Inquiry. 6(1): 125-130.

Goodman, N. 1981. "Routes of Reference". Critical Inquiry. 8(1): 121-132.

Goodman, N. and Elgin, C. Z. 1988. Reconceptions in Philosophy. Indianapolis: Hackett.

Margolis, J. 1981. "What Is When? When Is What? Two Questions for Nelson Goodman". Journal of Aesthetics and Art Criticism. 39(3): 266-268.

Matravers, D. 1998. Art and Emotion. Oxford: Clarendon.

Matravers, D. 2005. "Art Expression and Emotion". Routledge Companion to Aesthetics. $2^{\text {nd }}$ edition. B. Gaut and D. M. Lopes (eds.). London: Routledge.

Robinson, J. 2000. "Languages of Art at the Turn of the Century". Journal of Aesthetics and Art Criticism. 58(3): 213-218.

Robinson, J. 2007. "Expression and Expressiveness". Postgraduate Journal of Aesthetics. 4(2): 19-41. Textor, M. 2008. "Samples as Symbols". Ratio. 21(3): 344-359.

Walton, K. L. 1973. "Pictures and Make-Believe". The Philosophical Review. 82(3): 283-319.

Wollheim, R. 1987. Painting as an Art. London: Thames and Hudson. 